\title{
Refractory Gastroesophageal Junction Adenocarcinoma
}

National Cancer Institute

\section{Source}

National Cancer Institute. Refractory Gastroesophageal Junction Adenocarcinoma. NCI

Thesaurus. Code C162538.

Gastroesophageal junction adenocarcinoma that does not respond to treatment. 